Loyalitas Kreativitas

Aldi Masyarakat Kreatif
P-ISSN 2722-2101, E-ISSN 2722-4201

Program Studi Ekonomi Manajemen Universitas Pamulang Jurnal LOKABMAS Kreatif Vol.02,No.01,Maret 2021 Hal.77-83

Email:jurnalkreatif.manajemen@gmail.com

\title{
PENDIDIKAN DAN PELATIHAN MEMBANGUN GENERASI MUDA YANG KOMPETEN DAN RELIGIUS
}

\author{
Ibrahim Bali Pamungkas, Arief Budiyanto, Wahyu Andri Wibowo, \\ Nanda Rodiyana, dan Laura Komala
}

Dosen Ekonomi Fakultas Ekonomi Universitas Pamulang

\begin{abstract}
Email: dosen01015@unpam.ac.id, dosen01433@unpam.ac.id, wahyuandri.wibowo@yahoo.com, nandadoni003@gmail.com, dosen01013@unpam.ac.id,
\end{abstract}

\begin{abstract}
ABSTRAK
Pengabdian ini berjudul Membangun Generasi Muda Yang Kompeten dan Religius. Dan berlokasi di Komunitas Arimbin (Anak Rimba Bintaro) komunitas yang sebagian besar kegiatannya berkaitan dengan dunia Pecinta Alam yang berlokasi di Pondok Pucung, Tangerang Selatan.

Tujuan pengabdian ini adalah untuk memberikan arahan dan juga bimbingan terhadap anggota Arimbin, terkait dengan pengembangan Kompetensi dan juga nilai - nilai religius individu. Metode pelaksanaan pengabdian ini dilakukan dalam beberapa tahap, yaitu. 1) Tahapan Pendahuluan; dalam tahapan ini meliputi kegiatan survei lapangan dan hubungan dengan objek lokasi pengabdian serta penyusunan rancangan kegiatan dan keluaran dari kegiatan tersebut. 2) Tahapan Sosialisasi; dalam tahapan ini tim yang sudah menyusun dan membentuk rancangan acara kemudian menyampaikan kepada pihak sekolah serta pelaksanaan beserta keluaran yang ditentukan. 3) Tahapan pelaksanaan; tahapan ini adalah pelaksanaan dari rancangan kegiatan yang telah ditetapkan.

Kesimpulan dari pengabdian ini adalah peserta (anggota Arimbin) mendapatkan serta memahami nilai-nilai religi yang dapat dipraktikan ke dalam kehidupan sehari-hari serta mengerti akan kompetensi yang dimiliki pada individu serta faktor-faktor yang dapat membuat serta meningkatkan kompetensi. Harapan dari kegiatan pengabdian ini adalah dapat membuka wawasan peserta agar bisa lebih mengembangkan diri terutama dalam hal kompetensi dan juga dapat mempraktikan nilai-nilai religi di dalam kehidupan sosial bermasyarakat.
\end{abstract}

\section{Kata Kunci: Pelatihan, Pendidikan, Religiusitas, Kompetensi, Remaja}

\begin{abstract}
This activity is entitled "Building a Competent and Religious Young Generation" and located in the Arimbin Community (Anak Rimba Bintaro), a community whose activities are mostly related to the world of Nature Lovers, located in Pondok Pucung, South Tangerang.

The purpose of this service is to provide direction and guidance to Arimbin members, related to competency development and also individual religious values. The method of implementing this service is carried out in several stages, namely. 1) Preliminary stages; This stage includes field survey activities and relationships with the object of the service location as well as the preparation of activity designs and the outputs of these activities. 2) Socialization
\end{abstract}


Loyalitas Kreativitas

Aldi Masyarakat Kreatif
P-ISSN 2722-2101, E-ISSN 2722-4201

Program Studi Ekonomi Manajemen Universitas Pamulang Jurnal LOKABMAS Kreatif Vol.02,No.01,Maret 2021 Hal.77-83

Email:jurnalkreatif.manajemen@gmail.com

Stages; in this stage the team that has compiled and formed the program design then submits it to the school and the implementation and the specified outputs. 3) Stages of implementation; this stage is the implementation of the activity design that has been determined.

The conclusion of this service is that participants (members of Arimbin) get and understand religious values that can be practiced in everyday life and understand the competencies that individuals have and the factors that can create and improve competence. The hope of this service activity is that it can open participants' insights so that they can further develop themselves, especially in terms of competence and can also practice religious values in social life in society.

\section{Keywords: Training, Education, Religiosity, Competence, Youth}

\section{PENDAHULUAN}

Masa remaja sering dikenal dengan istilah masa pemberontakan. Pada masa-masa ini, seorang anak yang baru mengalami pubertas seringkali menampilkan beragam gejolak emosi, menarik diri dari keluarga, serta mengalami banyak masalah, baik di rumah, sekolah, atau di lingkungan rumah maupun di lingkungan pertemanannya (Unayah \& Sabarisman, 2015)

Dan dengan adanya arus globalisasi yang pesat serta kemajuan zaman dapat berdampak kepada sendi kehidupan. Tidak terkecuali kehidupan remaja (baca: generasi muda). Menurut (Reza, 2013) hal tersebut dapat memberikan dampak positif maupun negatif bagi kehidupan remaja. Remaja yang menunjukkan perilaku sesuai dengan norma dan nilai yang berlaku, maka remaja dikatakan memiliki moralitas. Sedangkan remaja yang menunjukkan perilaku bertentangan dengan norma dan nilai yang berlaku, maka remaja dikatakan melakukan tindakan amoral.

Menurut Santrock (2007) dalam (Aviyah \& Farid, 2014) faktor-faktor yang mempengaruhi kenakalan remaja yaitu. (1) Identitas, (2) Kontrol diri (3) Usia, (4) Jeniskelamin, (5) Harapan terhadap pendidikan dan nilai-nilai di sekolah, (6)
Proses keluarga, (7) Pengaruh teman sebaya, (8) Kelas sosial eko- nomi, (9) Kualitas lingkungan sekitar tempat tinggal. Di samping faktor-faktor tersebut, berdasarkan temuan penelitian sebelumnya religiusitas juga merupakan salah satu faktor yang menyebabkan kenakalan remaja.

Berdasarkan dari beberapa literasi yang telah disebutkan di atas penting dalam generasi muda khususnya kepada remaja untuk selalu mempelajari serta memahami proses keagamaan serta kompetensi dimana hal tersebut diharapkan tidak hanya akan berdampak kepada perilaku individu sehari-hari tetapi juga berdampak terhadap lingkungan secara luas. Dalam artikel kali ini, akan dibahas mengenai kompetensi dan pentingnya memahami religiusitas serta beberapa faktor yang berkaitan dengan hal tersebut. Agar dapat dijadikan sebagai khasanah literasi dan keilmuan bagi yang ingin mengembangkan hal tersebut.

\section{RUMUSAN MASALAH}

Dengan melihat latar belakang yang telah diutararakn di atas, kami berinisiatif untuk melakukan kegiatan Pengabdian Kepada Masyarakat agar dapat membantu dalam hal ini generasi muda (pelajar) untuk dapat 


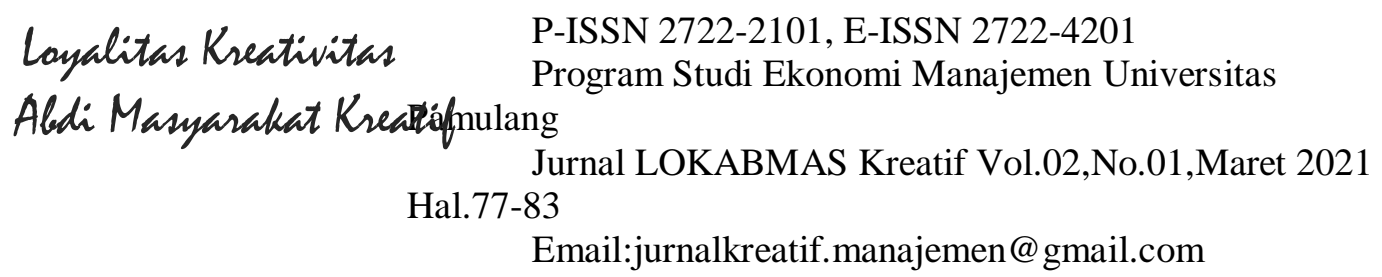

mengenali kompetensi dan religiusitas yang diharapkan dapat memberikan dampak khususnya di bidang kehidupan sosial pada umumnya.

\section{TUJUAN PELAKSANAAN}

1. Memperkenalkan kompetensi dan berbagai macam-macam ukuran sebuah kompetensi serta faktor-faktor yang berkaitan dengan hal tersebut.

2. Mendorong generasi muda untuk memperkenalkan serta memahami ukuran-ukuran sebuah religiusitas (komitmen beragama) sehingga dapat mengaplikasikannya dalam kehidupan sehari-hari dan tercermin dalam tingkah laku sehari-hari sehingga terhindar dari hal-hal yang menyimpang dan melawan hukum.

\section{TINJAUAN PUSTAKA}

\section{Generasi Muda (Milennial)}

Generasi muda saat ini adalah generasi milennial yang diartikan oleh Yuswohady (2016) dalam (Najoan, 2020) generasi yang lahir dalam rentang waktu awal tahun 1980 - 2000. Disebut generasi millennial dikarenakan merekalah generasi yang hidup dalam di pergantian millennium dan secara bersamaan dengan teknologi digital yang merasuk ke dalam sendi kehidupan sosial.

Lebih lanjut, (Najoan, 2020) dengan mengutip pendapat Kilber (2014) menambahkan bahwa karakteristik yang terbentuk pada generasi millennial adalah kecanduan internet, percaya diri dan harga diri yang tinggi, lebih terbuka dan bertoleransi terhadap perubahan, memperlihatkan gaji dan pemberian pengakuan terhadap individu; jadwal kerja yang flexibel.
Sedangkan menurut Sugiharti (2014) dalam (Hariyanti, 2017) Generasi Muda Muslim saat ini adalah bagian dari net generation yaitu sebuah generasi yang merupakan sebuah komunitas cyberspace yang paling dinamis dan menjadi aktor yang aktif membangun interaksi dan memanfaatkan jejaring dalam dunia maya karena net generation tumbuh besar dalam konteks akselerasi perkembangan teknologi informasi yang luar biasa cepat. Pada dasarnya net generation merupakan generasi techno-literate, di mana mereka memiliki ketergantungan yang tinggi pada teknologi informasi dalam menjalankan aktivitas hariannya.

Masa Remaja; Menurut Hurlock (1999) dalam (Unayah \& Sabarisman, 2015) ciri ciri masa remaja sebagai berikut;

1. Masa remaja sebagai periode yang penting, karena perkembangan fisik, mental yang cepat dan penting dan adanya penyesuaian mental dan pembentukan sikap, nilai dan minat baru

2. Masa remaja sebagai periode peralihan, adanya suatu perubahan sikap dan perilaku dari anak-anak ke menuju dewasa

3. Masa remaja sebagai periode perubahan, karena ada 5 perubahan yang bersifat universal yaitu perubahan emosi, tubuh, minat dan pola perilaku, dan perubahan nilai

4. Masa remaja sebagai usia bermasalah, karena pada masa kanak-kanak masalah- masalahnya sebagian besar diselesaikan oleh guru dan orang tua sehingga kebanyakan remaja kurang 
Layalitas Kreativitas P-ISSN 2722-2101, E-ISSN 2722-4201

Program Studi Ekonomi Manajemen Universitas

Aldi Masyarakat Kreatioffinulang

Hal.77-83

Jurnal LOKABMAS Kreatif Vol.02,No.01,Maret 2021

Email:jurnalkreatif.manajemen@gmail.com

berpengalaman dalam mengatasi

masalah

5. Masa remaja sebagai masa mencari identitas, karena remaja berusaha untuk menjelaskan siapa dirinya, apa peranannya

6. Masa remaja sebagai usia yang menimbulkan ketakutan, karena adanya anggapan stereotip budaya bahwa remaja adalah anak-anak yang tidak rapih, yang tidak dapat dipercaya dan cenderung merusak, menyebabkan orang dewasa harus membimbing dan mengawasi.

7. Masa remaja sebagai masa yang tidak realistik. Karena remaja melihat dirinya sendiri dan orang lain sebagaimana yang diinginkan dan bukan sebagaimana adanya terlebih dalam cita-cita

8. Masa remaja sebagai ambang masa dewasa, karena remaja mulai memusatkan diri pada perilaku yang dihubungkan dengan orang dewasa

\section{KOMPETENSI}

Menurut (Sedarmayati, 2013) kompetensi merupakan: "Karakteristik mendasar yang dimiliki seseorang yang berpengaruh langsung terhadap, atau dapat memprediksikan kinerja yang sangat baik". Kompetensi yang dimiliki pegawai baik secara individual harus dapat mendukung pelaksanaan strategi organisasi dan mampu mendukung setiap perubahan yang dilakukan manajemen.

Menurut Mitrani (1995) dalam (Ardiana \& Brahmayanti, 2010) mengartikan kompetensi sebagai suatu sifat dasar seseorang yang dengan sendirinya berkaitan dengan pelaksanaan suatu pekerjaan secara efektif atau sangat berhasil. Ketidaksamaan dalam kompetensi-kompetensi inilah yang membedakan seseorang pelaku unggul dari perilaku yang berprestasi rata-rata.

Sedangkan Narimawati (2010) dalam (Prayogi, Lesmana, \& Siregar, 2019) menjelaskan bahwa indikator kompetensi dapat dibagi menjadi tiga yaitu.

1. Kompetensi intelektual karakter sikap dan perilaku atau kemauan dan kemampuan intelektual individu (dapat berupa pengetahuan, keterampilan, pemahaman profesional, pemahaman konseptual dan lain-lain) yang bersifat relatif stabil ketika menghadapi permasalahan di tempat kerja, yang dibentuk dari sinergi antara watak konsep diri.

2. Kompetensi emosional adalah karakter sikap dan perilaku atau kemauan dan kemampuan untuk menguasai diri dan memahami lingkungan secara objektif dan moralis sehingga pola emosinya relatif stabil dalam menghadapi permasalahan ditempat kerja, yang dibentuk dari sinergi antara watak konsepdiri. Motivasi internal, serta kapasitas pengetahuan emosional,

3. Kompetensi sosial adalah karakter sikap dan perilaku atau kemauan dan kemampuan untuk membangun simpul-simpul kerja sama dengan orang lain yang relatif bersifat stabil ketika menghadapi permasalahan di tempat kerja yang terbentuk melalui sinergi antara watak, konsep diri 


\section{Loyalitas Kreativitas P-ISSN 2722-2101, E-ISSN 2722-4201 \\ Program Studi Ekonomi Manajemen Universitas \\ Aldi Masyarakat Kreatiofnulang \\ Hal.77-83 \\ Jurnal LOKABMAS Kreatif Vol.02,No.01,Maret 2021 \\ Email:jurnalkreatif.manajemen@gmail.com}

motivasi internal serta kapasitas pengetahuan sosial konseptual.

\section{RELIGIUSITAS}

Menurut (Aviyah \& Farid, 2014) Religiusitas adalah internalisasi nilai-nilai agama dalam diri seseorang. Internalisasi di sini berkaitan dengan kepercayaan terhadap ajaran-ajaran agama baik di dalam hati mau- pun dalam ucapan. Kepercayaan ini kemudian diaktualisasikan dalam perbuatan dan tingkah laku sehari-hari.

Sedangkan menurut Worthington, dkk (2003) dalam (Utama \& Wahyudi, 2016) menjelaskan religiusitas (komitmen beragama) sebagai sejauh mana seseorang menganut nilai-nilai agama, keyakinan dan praktiknya, dan menggunakannya dalam kehidupan sehari-hari. Lebih lanjut dijelaskan bahwa Religiusitas atau komitmen beragama dibagi menjadi dua jenis komitmen yaitu keagamaan intrapersonal yang berasal dari keyakinan dan sikap individu, dan komitmen agama interpersonal yang berasal dari keterlibatan individu dengan komunitas atau organisasi keagamaan.

Nuqul (2003) dalam (Hadjam \& Nasiruddin, 2003) mendefinisikan religiusitas sebagai kecenderungan. individu untuk memandang segala macam bentuk kehidupan dan peristiwa baik yang positif maupun. negatif sebagai suatu kesatuan dan dihubungkan dengan keseluruhan nilai kehidupan dengan Tuhan (Allah SWT). Ada beberapa indikator yang dapat digunakan untuk mengukur religiusitas seseorang, yaitu.

\section{Keyakinan Ideologis}

2. Praktik Keagamaan

3. Pengalaman Religius

4. Pengetahuan Agama

5. Konsekuensi

\section{METODE PELAKSANAAN}

Metode pelaksanaan kegiatan ini dilakukan dalam 3 (tiga) rangkaian tahapan, yaitu; Pertama tahapan Pendahuluan, Kedua tahapan Sosialisasi dan Ketiga adalah tahapan Pelaksanaan.

1. Adapun tahapan Pendahuluan meliputi kegiatan survei lapangan dan hubungan dengan objek lokasi pengabdian serta penyusunan rancangan kegiatan dan keluaran dari kegiatan tersebut.

2. Tahapan Sosialisasi; dalam tahapan ini tim yang sudah menyusun dan membentuk rancangan acara kemudian menyampaikan kepada pihak tempat objek pelaksanaan pelaksanaan beserta keluaran yang ditentukan.

3. Dan terakhir adalah Tahapan pelaksanaan; tahapan ini merupakan pelaksanaan dari rancangan kegiatan yang telah ditetapkan

\section{HASIL DAN PEMBAHASAN}

Pengabdian Kepada Masyarakat (PKM) yang merupakan salah satu Tridharma Perguruan Tinggi adalah sesuatu yang wajib dilakukan oleh setiap Dosen tidak terkecuali Dosen dari Universitas Pamulang. Pada pelaksanann kali ini, yang menjadi objek PKM adalah komunitas 


\section{Loyalitas Kreativitas P-ISSN 2722-2101, E-ISSN 2722-4201 \\ Program Studi Ekonomi Manajemen Universitas \\ Aldi Masyarakat Kreatiofnulang \\ Hal.77-83 \\ Jurnal LOKABMAS Kreatif Vol.02,No.01,Maret 2021 \\ Email:jurnalkreatif.manajemen@gmail.com}

(Anak Rimba Bintaro) Yaitu sebuah komunitas anak-anak muda yang beriorentasi serta mengaktulisasikan sebagian besar kegiatannya ke dalam lingkungan Pecinta Alam dan berlokasi di daerah Bintaro - Pondok Pucung - dan dilaksanakan pada tanggal $10-16$ Oktober 2020. Pelaksanaan dilakukan dengan bentuk penyuluhan dan pemberian materi yang berkaitan dengan tema yang diusung.

Dengan adanya kegiatan ini, diharapkan adanya sumbangsih baik itu dalam segi pemikiran, wawasan serta implementasi keilmuan yang dipelajari di Perguruan Tinggi bisa dibawah ke ranah praktis kehidupan.

\section{KESIMPULAN DAN SARAN}

\section{Kesimpulan}

Peserta memahami dan mengerti akan nilai - nilai religius dalam setiap individu dan kemudian diharapkan mampu mengaplikasikannya ke dalam kehidupan sehari-hari baik secara individu maupun sosial. Serta mengerti akan halnya mengenai pentingnya kompetensi yang harus dimiliki oleh setiap individu untuk dapat mengatasi pelbagai problem yang ada.

\section{Saran}

Dalam penyusunan acara kedepannya lebih diperhatikan terkait dengan penyesuaian materi dengan peserta pelatihan/penyuluhan agar tidak terjadi misinformasi dari peserta akibat gap peserta dengan materi. Materi yang disampaikan ditambahkan dengan video maupun narasi-narasi terkini yang berkaitan langsung dengan materi. Sehingga peserta dapat lebih memahami konteks pembahasan materi.

\section{DAFTAR PUSTAKA}

Ardiana, I. D. K. R., \& Brahmayanti, I. A. (2010). Kompetensi SDM UKM dan Pengaruhnya Terhadap Kinerja UKM di Surabaya. Jurnal Manajemen Dan Kewirausahaan, 12(1), 42-55. https://doi.org/10.9744/jmk.12.1.pp.4 2-55

Aviyah, E., \& Farid, M. (2014). Religiusitas, Kontrol Diri dan Kenakalan Remaja. Persona:Jurnal Psikologi Indonesia, 3(02), 126-129. https://doi.org/10.30996/persona.v3i0 2.376

Elburdah, R. P., Pasaribu, V. L. D., Rahayu, S., Septiani, F., \& Metarini, R. R. A. (2021). MOMPRENEUR PENOPANG PEREKONOMIAN KELUARGA DI MASA PANDEMI COVID-19 DENGAN BISNIS ONLINE PADA KELURAHAN PONDOK BENDA. Abdi Laksana: Jurnal Pengabdian Kepada Masyarakat, 2(1), 75-82.

Hulasoh, E., Virby, S., \& Tilova, N. (2018). Pengenalan Kosakata Bahasa Inggris Melalui Media Storytelling. Jurnal Pengabdian Dharma Laksana, 1(1), 101-110.

Hadjam, M., \& Nasiruddin, A. (2003). Peranan Kesulitan Ekonomi, Kepuasan Kerja Dan Religiusitas Terhadap Kesejahteraan Psikologis. Jurnal Psikologi UGM, 30(2), 72-80. https://doi.org/10.22146/jpsi

Hariyanti, P. (2017). Generasi Muda Muslim dan Gerakan Sosial Spiritual Berbasis Media Online. Jurnal ILMU KOMUNIKASI, 13(2), 165-178. https://doi.org/10.24002/jik.v13i2.67 1

Najoan, D. (2020). Memahami Hubungan Religiusitas Dan Spiritualitas Di Era Milenial. Educatio Christi, 1(1), 6474. Retrieved from file:///D:/S3/Novelty/Najoan2020.pdf 


\section{Loyalitas Kreativitas}

P-ISSN 2722-2101, E-ISSN 2722-4201

Aldi Masyarakat Krearidnulang

Program Studi Ekonomi Manajemen Universitas

Hal.77-83

Jurnal LOKABMAS Kreatif Vol.02,No.01,Maret 2021

Email:jurnalkreatif.manajemen@gmail.com

Prayogi, M. A., Lesmana, M. T., \&

Siregar, L. H. (2019). Pengaruh

Kompetensi Dan Disiplin Kerja

Terhadap Kinerja Pegawai Bank.

Festival Riset Ilmiah Manajemen

Dan Akuntansi, 6(2), 665-669. https://doi.org/10.35137/jmbk.v6i2.1 86

Priadi, A., Pasaribu, V. L. D., Virby, S., Sairin, S., \& Wardani, W. G. (2020). Penguatan Ekonomi Kreatif Berbasis Sumber Daya Desa Dikelurahan Rempoa. Abdi Laksana: Jurnal Pengabdian Kepada Masyarakat, 1(3), 356-358.

Reza, I. F. (2013). Hubungan Antara Religiusitas Dengan Moralitas Pada Remaja Di Madrasah Aliyah (Ma). HUMANITAS:

Indonesian Psychological Journal, 10(2), 45-57. https://doi.org/10.26555/humanitas.v 10i2.335

Sedarmayati. (2013). Manajemen Sumber Daya Manusia: Reformasi Birokrasi dan Manajemen Pegawai Negri Sipil. Bandung: Refika Aditama.

Unayah, N., \& Sabarisman, M. (2015). Fenomena Kenakalan Remaja dan Kriminalitas. Sosio Informa, 1(2),

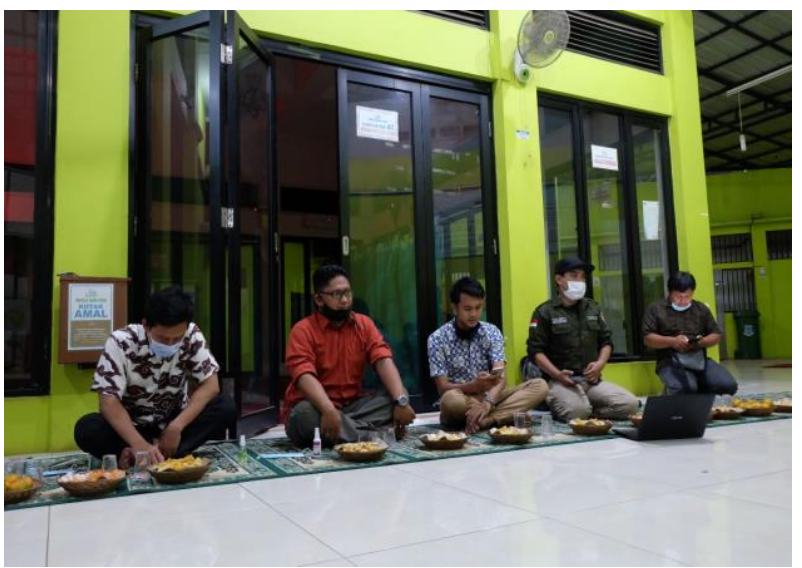
121-140.

Utama, A., \& Wahyudi, D. (2016). Pengaruh Religiusitas terhadap Perilaku Kepatuhan Wajib Pajak Orang Pribadi di Provinsi DKI Jakarta. Jurnal Lingkar Widyaiswara, 3(2), 1-13.

\section{DOKUMENTASI FOTO KEGIATAN}

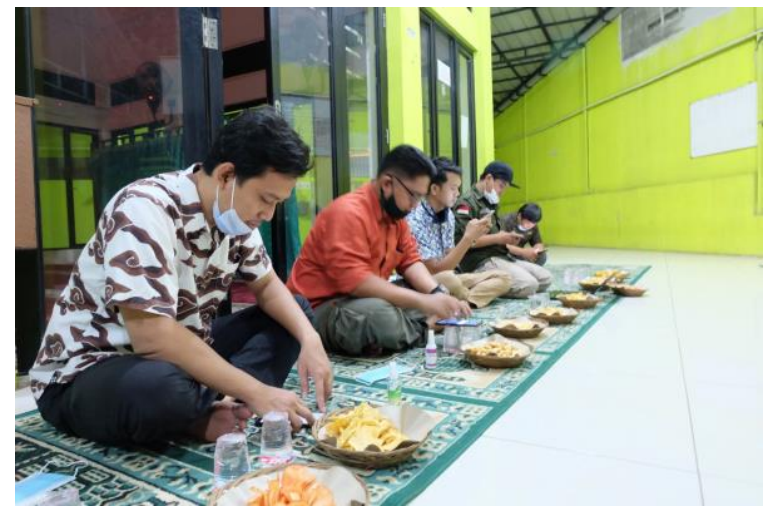

